\title{
VINTE ANOS DA CONVENÇÃO DE BELÉM DO PARÁ E A LEI MARIA DA PENHA
}

\author{
Lourdes Maria Bandeira \\ Universidade de Brasília (UnB) \\ Tânia Mara Campos de Almeida \\ Universidade de Brasília (UnB)
}

\begin{abstract}
Resumo: Em 2014, completaram-se duas décadas da Convenção Interamericana para Prevenir, Punir e Erradicar a Violência Contra a Mulher (Convenção de Belém do Pará), que é a base original da Lei no 11.340 (Lei Maria da Penha) e que continua a ser a referência para seu entendimento sociojurídico e a dimensionar sua eficácia. Nas comemorações destes 20 anos, vê-se maior precisão das compreensões e do desdobramento da Convenção, alcançados a partir das iniciativas tomadas pelos Estados signatários. Em um processo de retroalimentação, o refinamento de seus termos e princípios vem impactando legislações e medidas, adotados individualmente, dentro das soberanias nacionais. O presente artigo desenvolve uma reflexão sobre a Convenção e sua atual importância para o enfrentamento da violência contra as mulheres no Brasil, indicando perspectivas futuras ao escopo da Lei Maria da Penha.

Palavras-chove: Convenção de Belém do Pará; Lei Maria da Penha; eficácia sociojurídica.
\end{abstract}

\section{Introdução: tempo de comemorações}

A Carta das Nações Unidas, elaborada em 1945, afirmou a garantia da proteção dos Direitos Humanos baseados na dignidade do ser humano e na igualdade entre homens e mulheres, ${ }^{1}$ como bem acentua Tathiana Haddad Guarnieri :

A Carta da ONU marca o envolvimento desse organismo internacional com as questões de gênero, abrindo caminho para mudanças históricas no âmbito das preocupações internacionais. As questões de gênero, antes relegadas ao domínio doméstico das jurisdições nacionais, passam em definitivo para o âmbito das considerações globais. Inicia-se, com isso, um processo internacional de codificação dos direitos das mulheres.

Copyright @ 2015 by Revista Estudos Feministas.

${ }^{1}$ Em 1945, apenas 30 dos 51 Estados-membros originais da organização concediam às mulheres direito de voto igual ao dos homens ou permitiam que ocupassem cargos públicos (Boutros BOUTROS-GHALI, 1996).

2 Tathiana Haddad GUARNIERI, 2010, p. 4. 
Por sua vez, a Declaração dos Direitos Humanos de 1948 reafirmou que os direitos humanos são inalienáveis, universais e que não reconhecem qualquer diferença da condição de gênero. Embora tais tratados explicitem a não discriminação - sob qualquer dimensão - que deva existir entre homens e mulheres, a história planetária tem evidenciado a sua violação sistemática. Por conseguinte e diante de tamanha evidência, emergiu a necessidade da realização sistemática de conferências e convenções, que atuem no sentido de reconhecer, assegurar e, sobretudo, implantar e garantir os direitos das mulheres no plano sociojurídico dos Estados nacionais.

Nessa direção, a primeira Conferência Mundial sobre a situação jurídica e social da mulher, convocada pela Comission on the Status of Women (CSW), foi realizada no México em 1975 e em coincidência com o Ano Internacional da Mulher. A Organização das Nações Unidas (ONU), então, retirou as questões de gênero, em definitivo, do âmbito particular dos Estados e as trouxe para a realidade internacional, tornando-as, com isto, preocupações globais, cujos objetivos foram: a) a plena igualdade de gênero e a eliminação de qualquer forma de discriminação por qualquer motivo de gênero; b) a plena participação das mulheres nos processos de desenvolvimento; e, por fim, c) a maior contribuição das mulheres à paz mundial. A partir desses objetivos, a ONU evidenciou especial preocupação com a persistência de leis e práticas culturais fundamentalistas em inúmeras sociedades, que mantinham as mulheres sob diferentes tipos de opressão. Na sequência, seguiram-se outras grandes reuniões, sendo que, em 2015, serão comemorados os 40 anos dessa primeira conferência. $^{3}$

Vale destacar que um dos resultados diretos desse novo "movimento", por parte da ONU, que foi a inclusão de um importante tratado de reconhecimento dos direitos das mulheres: a Convenção sobre a Eliminação de Todas as Formas de Discriminação contra as Mulheres (Cedaw), adotada pela Assembleia Geral em 1979.4 Além disso, foi realizada a Conferência Internacional sobre Direitos Humanos, em Viena (Áustria), em 1993, que reafirmou os direitos humanos das mulheres.

Em setembro de 2014, completaram-se os 20 anos da Convenção Internacional sobre População e Desenvolvimento (CIPD), conhecida por Convenção do Cairo, que instituiu internacionalmente as bases para uma visão de desenvolvimento socioeconômico fundada no reconhecimento da pessoa como sujeito de direito, com especial destaque para a mulher. Em 1994, foi elaborado um relatório, atualmente ratificado por 179 países, que traçou as iniciativas no âmbito da sociedade civil para assegurar a igualdade, os direitos, a educação, a saúde, o ambiente e a redução da pobreza. Ainda em 1994, foi aprovada uma agenda cujos conteúdos colocavam os diversos governos no mais elevado compromisso com as expectativas das organizações e dos movimentos de mulheres e feministas, de juventudes, da diversidade sexual, pela liberdade religiosa, contra todas as formas de discriminação. ${ }^{5}$

Em setembro de 2015, completarão os 15 anos do estabelecimento dos Oito Objetivos de Desenvolvimento do Milênio (ODMs), que se constituem em um conjunto de metas organizadas pelos governos de 191 países-membros da ONU, que foram ordenadas em setembro de 2000 . Foram propostos como forma de solucionar alguns dos agudos problemas da humanidade, como a pobreza, a fome e a desigualdade entre os gêneros. Os ODMs estão implicados com a melhoria da condição de vida das mulheres. Destacam-se dois deles em especial: o objetivo três, pela igualdade entre os sexos e a valorização da mulher;

${ }^{3}$ Consultar: Leila Linhares BARSTED e Jacqueline PITANGUY, 2011.

${ }^{4}$ Leila Linhares BARSTED, 1995 e 2001.

${ }^{5}$ Consultar: Tania PATRIOTA, 1994. 
e o objetivo cinco, para a melhoria da saúde da gestante e a redução da mortalidade materna. Os ODMs surgem, a partir da Declaração do Milênio das Nações Unidas, de um esforço para sintetizar acordos internacionais alcançados em várias cúpulas mundiais ao longo dos anos 1990 (sobre meio ambiente e desenvolvimento, direitos das mulheres, desenvolvimento social, racismo, etc). A Declaração estabelece compromissos concretos que, se cumpridos nos prazos fixados e de acordo com os indicadores quantitativos que os acompanham, deverão melhorar o destino da humanidade neste século, com expectativa de serem alcançados até $2015 .^{6}$

Também, em setembro de 2015, serão comemorados os 20 anos da IV Conferência das Nações Unidas sobre a Mulher, realizada em Beijing/China em 1995 e em sequência às conferências organizadas anteriormente (México-1975, Copenhague-1980 e Nairobi-1985). Além de ter mobilizado grande número de mulheres a discutir temas de significativa relevância, contou com a participação de 300 representantes da delegação brasileira, um número expressivo de membros não governamentais. Nela foram introduzidos novos conceitos referentes às questões de gênero, com vistas à autonomia e equidade da mulher no planeta.

A realização da IV Conferência Mundial sobre a Mulher coincidiu com os 50 anos da ONU e, através do subtema "igualdade, desenvolvimento e paz", reafirmou o compromisso com os direitos humanos das mulheres, dando continuidade à agenda global para o progresso e fortalecimento da condição feminina no mundo. Elaborada na ocasião, a Plataforma de Ação de Pequim, com 361 parágrafos, traz um diagnóstico da situação da mulher no mundo, estabelecendo um conjunto de medidas que devem ser tomadas pela comunidade internacional com vistas a promover a capacitação das mulheres e a superação das discriminações de gênero. ${ }^{7}$

A Plataforma de Ação foi inovadora em três principais dimensões: 1) a elaboração de um conceito de gênero, segundo o qual as relações entre homens e mulheres são vistas como resultado de padrões sociais e culturais, o que permite sua modificação; 2) a noção de empoderamento da mulher, que ressalta a importância da postura feminina ativa sobre seu desenvolvimento, com a participação do governo e da sociedade na criação das condições para que isso ocorra; e, 3) a ideia de transversalidade, que garante que a perspectiva de gênero seja incorporada em todos os temas abrangidos pelas políticas públicas. ${ }^{8}$

Progressivamente, as convenções e os tratados assinados no âmbito internacional foram conquistando maior espaço para as demandas feministas no delineamento das políticas públicas.

Finalmente, dentre eventos e comemorações passados e em andamento, a centralidade deste artigo recai sobre as duas décadas da Convenção Interamericana para Prevenir, Punir e Erradicar a Violência Contra a Mulher, nominada Convenção de Belém do Pará (1994-2014). De 22 a 24 de outubro de 2014, foi realizada, na cidade do México, a $1^{\mathrm{a}}$. Conferência Extraordinária dos Estados Partes da Convenção que contou com a presença de representantes de 35 países, majoritariamente da América Latina e do Caribe. A reunião integrou as atividades de competência do Mecanismo de Seguimento da Convenção de Belém do Pará (Mesecvi), coordenada pela Comissão Interamericana de Mulheres (CIM). Na ocasião, foi lançado o Guía para la Aplicación de la Convención Interamericana para Prevenir, Sancionar y Erradicar la Violencia contra la Mujer. ${ }^{9}$

\footnotetext{
${ }^{\circ}$ OBJETIVOS DE DESENVOLVIMENTO DO MILÊNIO, 2010.

${ }^{7}$ Miriam ABRAMOVAY, 1995; Sonia CORRÊA, 1995.

${ }^{8}$ Patrícia Gay Pepper da COSTA, 1997; BARSTED, 2001; GUARNIERI, 2010

9 GUIA PARA LA APLICACIÓN de la Convención Interamericana para Prevenir, Sancionar y Erradicar la Violencia contra la Mujer, 2014.
} 
Foi com base nessa Convenção que o consórcio de Organizações Não Governamentais (ONGs) feministas, em parceria com a Secretaria de Política para as Mulheres (SPM), propôs a Lei $n^{\circ} 11$.340, aprovada em 7 de agosto de 2006, no Brasil. ${ }^{10}$ Conhecida popularmente como Lei Maria da Penha, ancorou suas definições fulcrais na referida Convenção, tanto que a ela se refere intensamente na Exposição de Motivos. " Portanto, seus atuais desdobramentos e o aprimoramento de seus elementos norteadores nestas duas décadas impactaram o enfrentamento da violência contra as mulheres no país.

É, então, a partir de uma reflexão sobre a Convenção de Belém do Pará e a Lei Maria da Penha que este artigo se desenvolve. Por um lado, recupera a história da Convenção, evidenciando seu marco de importância e, assim, rendendo-lhe justa homenagem. Por outro lado, analisa sua presença na configuração inicial da Lei Maria da Penha, em parte de sua eficácia e no horizonte futuro de possíveis novos entendimentos a seu respeito, tendo em vista o balanço destes 20 anos da Convenção e o relançamento de algumas de suas referências intrínsecas.

Afinal, a destacada relevância da Convenção circunscreve-se ao fato de se constituir pioneira e ainda se manter nesse lugar de vanguarda simbólica, legislativa e jurídica internacional em âmbito supra continental, pois "fue el primer tratado vinculante en el mundo em reconocer que la violencía contra la mujer constituye uma violación sancionable de direchos humanos", declarou Linda Poole, ${ }^{12}$ que, na ocasião de sua ratificação pelos Estados-partes, era a secretária executiva da Comissão Interamericana de Mulheres (CIM).

\section{Antecedentes: gênese da Comissão Interamericana de Mulheres (CIM)}

A CIM é um organismo especializado do Sistema Interamericano da Organização dos Estados Americanos (OEA), criado em 1928, durante a $6^{a}$ Conferência Internacional Americana, inicialmente, sediada em Havana (Cuba). De caráter permanente e constituindo-se o pioneiro organismo intergovernamental, no mundo, foi criado para assegurar o reconhecimento dos direitos humanos das mulheres, "en uma época em que el sufrágio feminino tan sólo se había logrado em los países americanos". ${ }^{13}$ Converteu-se no principal fórum de debate e formulação de políticas sobre os direitos das mulheres e a igualdade de gênero nas Américas. Quando criada, a CIM atuava no âmbito da União Pan-Americana, porém, com o fim desse organismo em 1948, foi incorporada à OEA como um Organismo Especializado de caráter técnico permanente. Sua sede atual é em Washington, D.C.

Segundo prescreve seu Estatuto, a finalidade da $\mathrm{CIM}^{14}$ é:

[...] promover e proteger os direitos da mulher e apoiar os Estados-membros em seus esforços para assegurar o pleno acesso aos direitos civis, políticos, econômicos, sociais e culturais que permitam que mulheres e homens participem em condições de igualdade em todos os âmbitos da vida social, para lograr que desfrutem plena e igualitariamente dos benefícios do desenvolvimento e compartam também a responsabilidade pelo futuro.

\footnotetext{
${ }^{10}$ BRASIL, 2006

${ }^{1}$ Pela Exposição de Motivos, n 16 de 11 de novembro de 2004, o Estado Brasileiro assenta-se na Convenção Belém do Pará, no Protocolo Facultativo à Convenção sobre a Eliminação de Todas as Formas de Discriminação contra a Mulher, além de outros instrumentos de Direitos Humanos (BRASIL, 2014).

${ }^{12}$ Linda POOLE, 2013, p. 9.

${ }^{13}$ Margarita ROQUE, 1998.

${ }^{14} \mathrm{~A}$ CIM é composta por delegadas de cada Estado-membro da OEA, designadas pelos governos nacionais A cada biênio ocorre assembleia entre elas, que tem por função formular políticas e especificar o programa de ação da Comissão.

${ }^{15}$ O Estatuto da CIM pode ser visualizado em: http://www.oas.org/xxxivga/portug/reference_docs/Estatuto_CIM.pdf.
} 
Tem como missão apoiar os Estados-membros da OEA em seus esforços para cumprir com os seus respectivos compromissos adquiridos internacional e interamericanos em matéria de direitos humanos das mulheres e equidade e igualdade de gênero, para que estes se convertam/transformem em políticas públicas efetivas contribuindo a uma plena e igualitária participação das mulheres. ${ }^{16}$

Ainda se destacam como parte de suas funções: formular estratégias direcionadas a transformar os papéis e a relação entre mulheres e homens nas esferas públicas e privadas; informar periodicamente à Assembleia Geral da OEA sobre os aspectos da condição da mulher no continente americano, evidenciando o progresso ocorrido nesse campo e os persistentes problemas relativos à condição de desigualdade; informar aos governos as recomendações que tendam a solucionar tais problemas; e, por fim, promover a adoção ou adequação de medidas de caráter legislativo, necessárias para eliminar a discriminação - as quais, no caso recente do Brasil, convergiu para a criação da Lei Maria da Penha.

A CIM tem, como mandato, velar pelos direitos e interesses das mulheres e, nesse sentido, identificou a presença de um vazio no texto da Convenção sobre a Eliminação de todas as Formas de Discriminação contra a Mulher (Cedaw) ${ }^{17}$ em relação a inserção da violência contra a mulher no campo jurídico-legislativo, uma vez que não a contemplava de maneira explícita. Por sua vez, a CIM tomou para si a tarefa de elaborar uma açãoestratégia multidimensional e multifocal para abordar tal questão. Foi deflagrado, em 1990, um processo de consulta a expertas, no âmbito interamericano sobre a situação "mulher e violência", envolvendo também a participação da sociedade civil em nível internacional e as instâncias de decisão da própria OEA. A consulta teve por objetivo iniciar os trabalhos de investigação e sistematização de propostas para regular - com legislações específicas - o fenômeno da violência contra as mulheres nas Américas, com vistas à sua erradicação. Como resultado desse processo, foi evidenciado que havia o predomínio universal de diversas formas e manifestações de violência contra a mulher, o que justificava a criação de medidas para combatê-las, sendo uma delas a de instigar a CIM a preparar um evento a respeito, com vistas a propor atuação própria no campo jurídico-administrativo, assim como de previsão legal e de políticas públicas.

Com base nessa situação, o Comitê Diretivo da CIM, considerou a possibilidade de convocar uma reunião para organizar uma convenção interamericana sobre mulher e violência, como parte de sua missão de estudar as formas e os meios para prevenir e para o enfrentamento da violência contra a mulher. Desse processo, resultou um anteprojeto de texto para a convenção, que circulou entre os governos durante o mês de novembro de 1991. A consulta foi ampliada, incluindo a comissão de parlamentares pertinentes, ministérios, outras agências governamentais, passando por associações profissionais e organizações da sociedade civil (ONGs), organizações de mulheres e de direitos humanos, em cada país da região. ${ }^{18}$

Concluídas as consultas, durante a realização da $6^{a}$ Assembleia Extraordinária de Delegadas da CIM, em abril de 1994, o projeto foi aprovado. Em junho do mesmo ano, durante $024^{\circ}$ período ordinário de sessões da Assembleia Geral da OEA, em Belém do Pará, a CIM apresentou o projeto: Convenção Interamericana para Prevenir, Punir e Erradicar a Violência Contra a Mulher (Convenção de Belém do Pará) ${ }^{19}$, que foi promulgada por

\footnotetext{
${ }^{16}$ Missão sistematizada a partir do art. $2^{\circ}$ do Estatuto da CIM.

17 CEDAW-1974, 1994.

${ }^{18}$ O referido texto do anteprojeto para a Convenção foi elaborado a partir do artigo de Linda POOLE, exsecretaria executiva da CIM, publicado em 2013

19 O texto integral pode ser acessado no site: http://artemis.org.br/wp-content/uploads/2013/11/revistaConvencao-Belem-do-Para.pdf.
} 
aclamação em 9 de junho de 1994. Entrou em vigor em 5 de março de 1995, tornando-se referência mundial ao enfrentamento à violência contra a mulher.

Aprovada pelo Brasil mediante o Decreto Legislativo $n^{\circ} 107$, de $1^{\circ}$ de setembro de 1995, foi em nosso solo ratificada em 27 de novembro de 1995. Até o momento foi ratificada por 32 dos 35 Estados-membros da OEA. Sem dúvida, representou um grande avanço para a compreensão e a visibilização da questão da violência ao dispor, entre outros itens, sobre a ampliação da definição de violência contra as mulheres, conforme seu artigo $1^{\circ}$ : "Para os efeitos desta Convenção, entender-se-á por violência contra a mulher qualquer ato ou conduta baseada no gênero, que cause morte, dano ou sofrimento físico, sexual ou psicológico à mulher, tanto na esfera pública como na esfera privada". ${ }^{20}$

A Convenção de Belém do Pará estabeleceu, pela primeira vez, o direito das mulheres viverem uma vida livre de violência, ao tratar a violência contra elas como uma violação aos direitos humanos. Nesse sentido, adotou um novo paradigma na luta internacional da concepção e de direitos humanos, considerando que o privado é público e, por consequência, cabe aos Estados assumirem a responsabilidade e o dever indelegável de erradicar e sancionar as situações de violência contra as mulheres.

No caso do Brasil, o cumprimento à legislação específica e própria, ancorada na Convenção de Belém do Pará, veio com a condenação do país pela Comissão Interamericana de Direitos Humanos (CIDH) da OEA, em abril de 2001. Após anos da denúncia a ela encaminhada em agosto de 1998, apresentada por Maria da Penha Fernandes e enviada conjuntamente pelo Centro de Justiça e Direito Internacional (Cejil) e pelo Comitê Latino-Americano de Defesa dos Direitos da Mulher (Cladem). A denúncia alegava a situação de extrema tolerância do Brasil com a violência cometida contra Maria da Penha pelo seu ex-esposo, que culminou com a tentativa de assassinato. A condenação do Brasil teve enorme repercussão midiática, em destaque foi a manchete na Folha de São Paulo: "OEA condena Brasil por violência doméstica. Comissão responsabiliza país por impunidade em caso de marido que deixou mulher paraplégica, há 18 anos". ${ }^{21}$

A comissão acusava o país de ter descumprido dois tratados internacionais, ${ }^{22}$ dos quais é signatário: a Convenção Americana de Direitos Humanos e a referida Convenção de Belém do Pará. Os dois acordos garantem às mulheres vítimas de violência doméstica amplo direito de defesa, enquanto os acusados de cometerem o delito devem ser alvo de investigação policial e judicial rigorosa, o que não ocorreu. A sentença da Comissão afirmou que "O Brasil não garantiu um processo justo contra o agressor em um prazo razoável". A CIDH analisou a denúncia por 13 anos e, durante esse tempo, foram enviadas três solicitações oficiais de esclarecimentos ao governo brasileiro, que não as considerou.

Após fazer o primeiro pedido de informação ao governo brasileiro, em 19 de outubro de 1998, a Comissão aguardou 250 dias por uma manifestação por parte da diplomacia brasileira antes de decidir dar prosseguimento ao processo. É fato que órgãos federais nunca encaminharam qualquer resposta sobre o caso Maria da Penha. Cumprindo as normas das Convenções Internacionais de Direitos Humanos, a Comissão acatou como verdadeira a denúncia feita pelas duas organizações não governamentais e condenou - Brasil. A justiça brasileira, na oportunidade, não se manifestou a propósito da condenação. No entanto, esse posicionamento repercutiu de maneira indelével no

20 BRASIL, 1995.

21 FOLHA DE SÃO PAULO, 2001, Caderno C, p. 5

${ }^{22}$ Esse processo está descrito detalhadamente no Relatório Anual 2000, no 54/01, com acesso disponível em: http://www.sbdp.org.br/arquivos/material/299_Relat\%20n.pdf.

506 Estudos Feministas, Florianópolis, 23(2): 501-517, maio-agosto/2015 
movimento feminista, ${ }^{23}$ o qual se sentiu desafiado a agir em relação à condenação do Brasil.

\section{Potencialidades da Convenção de Belém do Pará}

O vigor ainda existente da Convenção de Belém do Pará pode ser verificado a partir das quatro premissas iniciais, destacadas no Guía para la Aplicación de la Convención Interamericana para Prevenir, Sancionar y erradicar la Violencia contra la Mujer - Convención de Belém do Pará. ${ }^{24}$ Estas servem de base à sua interpretação oficial atual e foram assim destacadas por terem servido, anteriormente, de parâmetros indicativos à formulação e aplicação de legislações no interior de países dela signatários, como, em particular, serviram de referência central à formalização da Lei Maria da Penha.

Ou seja, há uma retroalimentação permanente entre o horizonte geral da Convenção e as particularidades estabelecidas e vivenciadas dentro de cada Estado no que toca ao tema mulher e violência. Ao se buscar colocar em prática a Convenção pelos Estadosmembros, acumulou-se uma experiência e agregou-se conhecimento sobre os planos emergidos na realidade das dificuldades e dos impedimentos à efetiva aplicação das legislações a partir de então geradas dentro de cada nação, como no que se refere à Lei Maria da Penha.

A primeira premissa: "A violência contra as mulheres constitui uma violação dos direitos humanos". ${ }^{25}$

Em 1993, a Conferência Mundial de Direitos Humanos realizada em Viena, através da Declaração de Viena, pronunciou-se a favor do reconhecimento dos direitos específicos das mulheres e elevou à categoria dos direitos humanos o direito das mulheres viverem sem violência. Afirmou-se, pela primeira vez, que os direitos da mulher e da menina são parte inalienável, integral e indivisível dos direitos humanos universais. Todas as formas de participação das mulheres em condição de igualdade, em todas as dimensões ou esferas da vida devem constituir-se em objetivos prioritários da comunidade internacional. Em outras palavras, hoje o reconhecimento da violência contra as mulheres como uma violação dos direitos humanos constitui-se em questão relevante na agenda pública mundial. Cada vez mais, a violência contra a mulher deixa de ser um problema de âmbito privado e se torna uma questão pública, conforme expresso no Guía, demandante de prevenção, erradicação e punição.

Os Estados obrigam-se a tomar medidas para combatê-la, o que significa que devem responder por atos e omissões de seus agentes, como por ações privadas que coloquem em risco a vida das mulheres. Nesse sentido, pode-se assegurar que a Convenção desenvolveu um novo marco teórico, prático e simbólico de proteção às mulheres no hemisfério americano, similar ao critério sustentado pela Cedaw, a partir de 1992, de que o Estado também pode ser responsável pelas iniciativas domésticas de violência e discriminação contra a mulher, em caso de não adotar as medidas com a devida diligência para coibi-las. A exigência de que o Estado intervenha adequadamente para combater tal tipo de violência sai do âmbito da discricionariedade e passa a constituir-se em direito protegido jurídica e internacionalmente, sendo reforçado nesse balanço dos 20 anos da Convenção.

${ }^{23}$ Consulta realizada no site: http://www.observe.ufba.br/lei mariadapenha

${ }^{24}$ GUIA PARA LA APLICACIÓN de la Convención Interamericaña para Prevenir, Sancionar y Erradicar la Violencia contra la Mujer, 2014.

${ }^{25}$ Esta e as demais premissas fazem parte do texto inicial do Tratado Internacional que adotou a Convenção Interamericana para Prevenir, Punir e Erradicar a Violência contra a Mulher, 1994. 
Para as mulheres em situação de violência, é dever do Estado oferecer prevenção, investigação, sanção e reparação. A justiça deve ser aplicada a partir de uma perspectiva de gênero. Ou seja, com essa perspectiva possibilitar-se-á romper com as formas tradicionais de aplicar a justiça, no sentido de remover as dificuldades postas ao inquérito, à credulidade sobre o depoimento da mulher, à não revitimização da mulher, à escuta contextualizada em cenário de poder e à impunidade do agressor. Para tanto, as autoridades judiciais devem ser cobradas pela plena diligência do processo e sua eficiência - e não apenas que este represente o rito mecânico de formalidades processuais e sem consideração da situação histórica em que se insere a opressão de gênero vivida pela mulher em situação de violência.

A segunda premissa: "A violência contra as mulheres é uma ofensa à dignidade humana e uma manifestação das relações de poder historicamente desiguais entre mulheres e homens."

O fenômeno da violência contra a mulher não é isolado. É complexo, multidimensional e perpassa todos os países, expressando-se de maneiras específicas, em espaços e tempos diferenciados. No entanto, possui uma raiz comum: a desigualdade que sofrem as mulheres. A Convenção identifica como principal, mas não única causa da violência contra a mulher, as relações desiguais de poder entre homens e mulheres constituídas em longa tradição e manifestas em variadas expressões. Tais relações desiguais são produtos de circunstâncias histórico-sociais que legitimam, tanto no plano legal como sociocultural, a violação dos direitos humanos das mulheres e das meninas. Por conseguinte, os direitos destas se tornam cada vez mais vulneráveis por ação ou por omissão da sociedade e do próprio Estado. Fato este acentuado pelos padrões socioculturais sexistas, que caracterizam as instituições e que tendem a reproduzi-los, ao desvirtuar o caráter grave de um ato de violência baseado na condição de gênero também por parte das instâncias governamental e judicial que deveria combatê-lo. Logo, medidas precisam ser adotadas nessa direção de constante autocrítica e revisão por parte dos Estados, além de se estabelecer intolerância em relação a qualquer uma destas manifestações.

O direito à igualdade deve constituir-se no princípio para que o Estado e seus respectivos ordenamentos jurídicos e legislativos não introduzam regulações e instrumentos de caráter discriminatórios e desiguais. Faz-se necessário o compromisso do Estado para assegurar medidas que reconheçam e assegurem a plena igualdade perante a lei, de acesso e de tratamento. Não obstante, muitas vezes, há necessidade de estabelecer certas distinções, mas que as mesmas sejam feitas com critérios razoáveis e legítimos.

A terceira premissa: "A violência contra a mulher transcende todos os setores sociais." Trata-se de um problema universal, na medida em que a violência suplanta todos os grupos sociais e culturais, assim como todos os setores de uma determinada sociedade. Tem proporções epidêmicas, cujas manifestações assumem características específicas e interseccionadas com vários marcadores simbólicos (raça, etnia, classe social, geração, dentre outros) em cada contexto sociocultural.

Apesar das múltiplas expressividades da violência sofrida pelas mulheres, todas apontam para a interseção entre a condição de subordinação baseada no gênero e outras formas de desigualdades que recaem sobre as mulheres em cenas sociais e institucionais específicas. Razões estas que tornam fundamental a atuação da Convenção neste momento para enfrentar a violência desde o âmbito político, jurídico, social, econômico, privado e público de modo transversal ao pressionar os Estados-membros a tomarem medidas nessa direção para, de fato, assegurarem o direito da mulher a uma vida livre de violência.

Por fim, a quarta premissa: "A eliminação da violência contra as mulheres é condição para o desenvolvimento igualitário." 
A violência contra a mulher cria limites ao desenvolvimento, em suas variadas vertentes. Ademais, impede-as dele participarem ativamente, restringindo sua capacidade de atuar. Em maioria, são as mulheres que vivem em situação de pobreza e que respondem pelas responsabilidades domésticas e de sustento da família, sendo sobre elas que recai a parte maior da desintegração social e das condições de vulnerabilidades. O impacto negativo da violência contra elas deve ser considerado, inclusive em sentido amplo, pois representa um volume de recurso financeiro não desprezível, ao mesmo tempo em que interfere no equilíbrio político de cada nação. Portanto, as questões relativas à condição de gênero devem constituir-se em prioridade nas agendas nacionais, deixando de ser destinadas a um lugar secundário e residual, como habitualmente têm sido tratadas.

As mulheres devem ter os seus direitos humanos garantidos, bem como o direito à liberdade, autonomia, segurança e dignidade, sem agressões físicas, psicológicas ou morais. Nenhuma mulher deve ser ameaçada, desrespeitada ou torturada. A integridade física remete à integridade psíquica - seu contrário compromete também as condições de saúde, incidindo, profundamente, sobre seus direitos sexuais e reprodutivos. Por fim, o direito à vida reveste-se de caráter essencial aos diversos níveis de desenvolvimento, uma vez que se constituem em um núcleo único e indissociável, devendo a mulher ser protegida pelos demais direitos previstos em todos os instrumentos regionais e internacionais relativos aos direitos humanos.

Essas quatro premissas foram, então, destacadas a partir da troca de informações e experiências que os governos estabeleceram entre si ao longo destas duas décadas da Convenção, aproveitando mutuamente boas ideias e práticas que cada um deles desenvolveu sobre como proteger as mulheres contra as discriminações e violências da sociedade. Nesse sentido, ressaltam-se, no Capítulo IV da Convenção, as exigências para que os governos dos países-membros prestem contas de suas ações em relação à implementação dos mecanismos interamericanos de proteção:

Artigo 10 - A fim de proteger o direito de toda mulher a uma vida livre de violência, os Estados-Partes deverão incluir nos relatórios nacionais à Comissão Interamericana de Mulheres informações sobre as medidas adotadas para prevenir e erradicar a violência contra a mulher, para prestar assistência à mulher afetada pela violência, bem como sobre as dificuldades que observarem na aplicação das mesmas e os fatores que contribuem para a violência contra a mulher.

Esse Artigo foi evidenciado durante a $1^{a}$ Conferência Extraordinária dos Estados Partes da Convenção de Belém do Pará (México, outubro de 2014). É marcada sua relevância neste momento de balanço e síntese das medidas adotadas no interior dos países signatários e de seu papel primordial ao articular atores sociais diversos - Estados, sociedade civil, organismos internacionais - em nova mentalidade e linguagem sociojurídica.

Para assegurar o cumprimento do Art. 10, foi criado o Mecanismo de Seguimento da Convenção de Belém do Pará (Mesecvi). Seu objetivo é dar continuidade e analisar como a Convenção está sendo implantada nos países-membros, assim como facilitar a cooperação entre os Estados-partes entre si e o conjunto de Estados-membros da OEA, contribuindo para a consecução dos propósitos da Convenção.

A criação do Mesecvi ocorreu durante a $31^{a}$. Assembleia de Delegadas da CIM realizada em Washington, em 2004. O fundamento central do Mesecvi norteia suas atribuições, mas os procedimentos empregados devem estar de acordo com a soberania de cada Estado-membro, com a não intervenção, assim como com respeito à Constituição

${ }^{26}$ CONVENÇÃO INTERAMERICANA para Prevenir, Punir e Erradicar a Violência contra a Mulher, 1994 
e aos princípios jurídicos de cada Estado-parte. ${ }^{27}$ No ano de criação da Lei Maria da Penha, 2006, os Estados-partes enviaram ao Mesecvi as respostas ao primeiro questionário referente ao cumprimento da Convenção.

No seu plano estratégico de 2013 a 2017, o Mecanismo destaca como sendo as principais metas: a) fortalecimento e garantia dos direitos humanos das mulheres a partir de uma visão de diversidade e interculturalidade; b) tornar o Mesecvi um paradigma hemisférico em matéria de direitos humanos e violência contra a mulher. ${ }^{28}$

Sem dúvida, a Convenção de Belém do Pará significou expressivo avanço em defesa dos direitos humanos das mulheres do continente. Estabeleceu que a violência contra a mulher envolve qualquer ação ou conduta baseada em seu gênero, que lhe cause morte, dano ou sofrimento físico, sexual e psicológico, tanto na esfera privada como pública. Ao mesmo tempo, trata-se de instrumento sociojurídico internacional pioneiro quanto ao problema endêmico da violência contra a mulher, que possibilita que a denúncia interna dos Estados seja deslocada ao plano internacional, como ocorreu com o caso Maria da Penha. Ademais, ampliou a definição de violência baseada na condição de gênero, rompendo com a definição conservadora centrada na violência física, descontextualizada das variadas, tradicionais e interseccionadas relações de poder, em suas transversalidades e com carga altamente nociva ao desenvolvimento democrático.

\section{Instituição da Lel Maria da Penha e seus desdobramentos}

A Lei Maria da Penha (LMP), que trata da violência doméstica e familiar contra a mulher, é fruto do engajamento do Estado brasileiro no sistema interamericano de proteção dos direitos humanos das mulheres. Como assinalam Valerio de Oliveira Mazzuoli e Alice Bianchini:

[...] a Comissão recomendou ao Brasil, dentre outras medidas, prosseguir e intensificar o processo de reforma que evite a tolerância estatal e o tratamento discriminatório com respeito à violência doméstica contra mulheres no país, particularmente o seguinte: a) medidas de capacitação e sensibilização dos funcionários judiciais e policiais especializados para que compreendam a importância de não tolerar a violência doméstica; b) simplificar os procedimentos judiciais penais a fim de que possa ser reduzido o tempo processual, sem afetar os direitos e garantias de devido processo; c) estabelecimento de formas alternativas às judiciais, rápidas e efetivas de solução de conflitos intrafamiliares, bem como de sensibilização com respeito à sua gravidade e às consequências penais que gera; d) multiplicar o número de delegacias policiais especiais para a defesa dos direitos da mulher e dotá-las dos recursos necessários à efetiva tramitação e investigação de todas as denúncias de violência doméstica, bem como prestar apoio ao Ministério Público na preparação de seus informes judiciais; e) incluir em seus planos pedagógicos, unidades curriculares destinadas à compreensão da importância do respeito à mulher e a seus direitos reconhecidos na Convenção de Belém do Pará de 1994, bem como ao manejo dos conflitos intrafamiliares. ${ }^{29}$

Em 2007, o Comitê Cedaw prescreveu o dever da República Federativa do Brasil de estruturar os juizados especializados no combate à violência contra a mulher, preconizados pela LMP, em todos os estados e no Distrito Federal. Atualmente, há o total de 87 juizados (ou

${ }^{27}$ GUIA PARA LA APLICACIÓN de la Convención Interamericana para Prevenir, Sancionar y Erradicar la Violencia contra la Mujer, 2014, p. 10, tradução das autoras.

${ }_{28}^{28}$ GUIA PARA LA APLICACIÓN de la Convención Interamericana para Prevenir, Sancionar y Erradicar la Violencia contra la Mujer, 2014, p. 66, tradução das autoras.

${ }^{29}$ Valério de Oliveira MAZZUOLI e Alice BIANCHINI [s.d.], p. 3. 
varas) nas 27 unidades da federação, incluindo o Distrito Federal. Não obstante o número significativo de juizados, este permanece ainda acanhado diante da demanda volumosa, o que significa que tal acesso especial à justiça encontra-se disponível para um contingente ainda bem reduzido de brasileiras, pouco atingindo as mulheres das zonas rurais, as mulheres indígenas e as mulheres negras. A criação dos juizados veio ao encontro dos ditames constitucionais que apregoam ter o Estado a responsabilidade de proteger todos os membros da família, além da mulher. Afinal, as bases constitucionais foram erguidas levando-se em conta a abordagem complexa e multidisciplinar do problema, permitindo que a violência doméstica e familiar passasse a ser tratada de forma bem mais abrangente e eficaz.

A partir da aprovação e implantação da LMP, esta tornou-se um marco importante à mitigação de casos ou situações impunes e à redução do índice de violência contra a mulher. Na sua letra, encontram-se indicações explícitas sobre uma gama articulada de decisões a serem tomadas para efetivar o enfrentamento à violência doméstica e familiar, deixando este fenômeno de ser um problema particular para se tornar um problema legítimo e de interesse público. Haja vista que se aponta para a necessidade de implantação e incremento de ações voltadas a uma complexa rede de atendimento multidisciplinar, tanto aos agressores como às mulheres agredidas ou àquelas que permanecem em situação de violência, que envolva instituições governamentais, magistratura, ministério público, defensoria pública e organizações da sociedade civil.

Também colabora para esse imbricamento, o caráter híbrido do alcance da lei que abrange conjuntamente a esfera penal e a cível em relação às denúncias, o que reforça a necessidade de articulação multilateral permanente - não desprovida de tensões - entre o campo jurídico e o das políticas públicas. E, por fim, destaca-se o fato de que a própria LMP envolve uma rede não somente para realizar a decisão legal, mas também para que os atos subsequentes, relacionados ao seu cumprimento, monitoramento e avaliação para além dos órgãos jurídicos competentes, sejam implementados.

Essa complexa interconexão entre saberes, instituições e intervenções na qual se ancora a LMP é uma novidade bem-vinda à dimensão pedagógica transformadora e de vanguarda dos direitos humanos das mulheres, cuja complexidade não a torna fácil de ser colocada em prática. Ranços limitadores dos procedimentos internos nos poderes e nos serviços envolvidos na sua aplicação, heranças da formação patriarcal e familista por parte dos/as agentes públicos/as responsáveis pela sua execução e entraves de recursos disponíveis para a criação e ampliação de equipamentos dificultam significativamente as boas respostas aos desafios colocados.

Evidentemente, os sistemas de saúde, justiça, segurança e assistência social têm papéis claros a cumprir no acompanhamento e desfecho dos casos de violência e, portanto, a atuação de cada um deles decorre das responsabilidades específicas que thes competem. A análise particular de um desses sistemas e dos efeitos de suas funções no que tange à aplicação da LMP não é por ora nosso objetivo, mas os princípios norteadores de núcleos de sentido envolvidos no entendimento da "eficácia" e de sua articulação com a Convenção Belém do Pará.

Do ponto de vista semântico, a palavra "eficácia" vem do latim efficere, eficaccia, efficax, que se refere "à produção dos efeitos esperados". Essa apropriação literal de significado é acionada pela teoria do direito, que é eficaz quando atinge sua finalidade esperada, qual seja, a de ser aplicada e obedecida pela sociedade. Todavia, o conceito de eficácia pode ter mais de um sentido.

Se estudada pela teoria do direito, a "eficácia" é tomada como aplicabilidade e obediência à norma, ou seja, analisa se as normas jurídicas estão sendo efetivamente 
aplicadas e obedecidas para se afirmar que o direito é eficaz; portanto, reina a lógica da obediência da lei. Para uma leitura no campo da Sociologia Jurídica, no entanto, importa compreender a "eficácia metajurídica", isto é, a faculdade que as normas têm de provocar efeitos substanciais (e não somente formais) para além dos quais elas foram criadas; isto é, a lei pode ter uma interpretação mais ampla, no sentido de que deve ultrapassar o recorte formal, mas considerá-la no contexto sociocultural histórico.

Ou seja, pode haver uma eficácia jurídica e uma eficácia social articuladas conjuntamente. A primeira responde a um conceito formal, segundo o qual uma norma emana de acordo com o ordenamento jurídico e torna-se eficaz juridicamente, podendo ser exigida a tornar-se obrigatória. Já a eficácia social existirá quando as pessoas sujeitas àquela norma a aceitam e obedecem, porque ela produz sentido à vivência coletiva e individual sujetiva. O conflito emerge quando uma norma pode ter eficácia jurídica, mas não ter eficácia social - como ocorre com diversas "leis que não pegam" no país. ${ }^{30}$ Ao contrário da LMP, que é conhecida pela maioria da população. ${ }^{31}$ Por conseguinte, a centralidade da eficácia jurídica e da eficácia social deveria constituir-se um único processo de prática social e política.

Na perspectiva feminista e dos direitos humanos das mulheres, consonante com o parágrafo $1^{\circ}$ do artigo $3^{\circ}$ da LMP, há a pressuposta conjugação da eficácia jurídica com a eficácia social, o que não significa que, na atuação concreta em âmbito do direito, a eficácia social seja contemplada.

O poder público desenvolverá políicas que visem garantir os direitos humanos das mulheres no âmbito das relações domésticas e familiares no sentido de resguardá-las de toda forma de negligência, discriminação, exploração, violência, crueldade e opressão. ${ }^{32}$

Além desse, há o artigo 60: "A violência doméstica e familiar contra a mulher constitui uma das formas de violação dos direitos humanos". Ambos são marcos que geram reformulações desafiadoras nos campos jurídico e das políticas públicas.

Com esse espírito de ampliação, é que a eficácia da LMP consolida-se, promovendo e provocando o entendimento sempre novo das situações transformadas em casos jurídicos, ao mesmo tempo em que tem vencido resistências ainda presentes em diferentes ordens de sua aplicação. Lidar com as leis, enquanto instrumentos da Modernidade, diante da variedade de relações sociais em que se articulam sujeitos múltiplos e diversas instituições é um grande desafio que demanda novas dinâmicas de distribuição de justiça, especialmente, em torno de sua administração pública e consequências nas instituições que integram o sistema de justiça criminal. Articular as diversas posições discursivas de cada sujeito, com suas singulares inscrições socioeconômica, racial e geracional (dentre outras), e os escopos particulares das instituições envolvidas na rede de enfrentamento à violência, implica em alargar as inúmeras possibilidades do texto normativo e das intervenções das políticas públicas em meio a limites e tensões daí decorrentes.

Inegável é a tomada de consciência por boa parte da população brasileira de negar a naturalização das situações de violência contra as mulheres, uma vez que a penetração de valores feministas influenciou (e influencia) tanto sua visibilidade como a afirmação dos estudos de gênero e sobre a violência. Paradoxalmente, é também inegável que a família e a esfera do privado representam valores ainda importantes ao universo

\footnotetext{
${ }^{30}$ A propósito consultar: André-Jean ARNAUD, 1999.

${ }^{31}$ DATASENADO, 2013.

32 BRASIL, 2006.
} 
jurídico. Assim, mesmo reconhecidos os avanços, estes não asseguram, necessariamente, o reconhecimento da igualdade entre homens e mulheres, no sistema de "justiça de gênero". Nancy Fraser (2002) explicita que, para a promoção de um sistema de "justiça de gênero", é fundamental que seja modificada a hierarquia de status/posição em que são colocados os homens e as mulheres perante as práticas das instituições, uma vez que estas - e dentre elas, o Poder Judiciário - perpetuam modelos de status diferenciado em relação à condição sexo/gênero que acaba por influenciar sua atuação jurídica. ${ }^{33}$ Isso evidencia as dificuldades e os limites existentes, postos na suposta neutralidade do direito manuseada por segmentos do Poder Judiciário no enfrentamento das questões de gênero.

Portanto, a construção de uma cultura jurídica feminista faz-se necessária, não apenas no âmbito político, mas também simbólico, pois, se as desigualdades (status, no dizer de Fraser) são patentes em nossa sociedade, o são ainda mais no direito penal que expressa percepções e desigualdades em relação às condições de gênero de longa tradição patriarcal. Ou seja, o direito penal facilmente (re)constrói ou ratifica tais desigualdades, ora colocando a mulher na posição de eterna revitimizada, ora colocandoa na condição de responsável pelo delito, sendo transformada de vítima em ré.

\section{Considerações finais}

A Convenção de Belém do Pará é o primeiro tratado específico sobre combater a violência contra a mulher, oriundo do continente sul-americano, e que está repercutindo de forma crucial em diversos países do globo terrestre. A América Latina é a região do mundo que mais avançou na criação de mecanismos sociojurídicos-legislativos para combater a violência contra a mulher. Violência esta que vem intensamente fazendo parte da vida cotidiana das mulheres. Segundo a pesquisa DataSenado, 700 mil brasileiras continuam sendo alvo de agressões atualmente. ${ }^{34}$ Foi a Convenção de Belém do Pará que abriu espaço formal para os países engajarem-se no combate à violência contra a mulher, assim como é ela que demarca uma nova fase na ordem jurídica internacional, contraditória ao poder político patriarcal.

Esse avanço inscreve-se na chamada segunda geração de tratados internacionais, que se ancoram na constituição de leis integrais. Amplia concepções e conceitos no âmbito do direito internacional, proporcionando a criação de novas práticas legislativas nos países e corroborando para a eliminação de práticas de impunidade, que devem ser incorporadas nas lógicas jurídicas nacionais. A Convenção representa o avanço do desenvolvimento democrático, oferecendo instrumentos conceituais e legais para o combate das bases assimétricas de poder existentes nas estruturas sociais, assim como das formas de poder e discriminação contra as mulheres que se retroalimentam permanentemente.

Nestes nove anos de vigência da Lei Maria da Penha, vê-se o esforço árduo para se estabelecer a transversalidade da problemática da violência contra as mulheres nas mais diversas esferas das políticas públicas de modo consonante com a Convenção. Sua eficácia social e jurídica tem requerido constante percepção, ação multidimensional e amplas parecerias com o Poder Judiciário, ministérios e demais instâncias, para dar-lhe legitimidade social e mostras de seu bom resultado.

Das articulações, em fina sintonia com os movimentos feminista e de mulheres pelo país afora, tem-se a possibilidade de ver em marcha a execução de uma política nacional tanto nos autorizados fóruns de disputa - os tribunais - como nas campanhas publicitárias

${ }^{33}$ Nancy FRASER, 2002.

${ }^{34}$ DATASENADO, 2013, p. 2. 
e na boca do povo. Demonstra que a LMP vem cumprido, apesar de algumas adversidades, com seu potencial discursivo e representacional, que permite validar e inscrever a existência de um sujeito coletivo, a partir de sua história de vários tipos de sofrimento, em seu texto: as mulheres brasileiras.

Ainda que os números de sentenças por ela produzidos ou o número de equipamentos para sua aplicação, por exemplo, estejam longe do desejado, sua capacidade para impactar e (re)modelar, com as categorias consagradas juridicamente, a mentalidade das pessoas, as crenças e os comportamentos naturalizados, os significados para o desvalor encarnado nas mulheres na tradição patriarcal retratam seu grande avanço. Ao utilizar o entendimento de Rita Laura Segato, podemos afirmar que está definitivamente em curso uma mudança de sensibilidade ética em nossa sociedade em meio à LMP.

En este sentido, el derecho y, en especial, los Derechos Humanos, se encuentran indisociablemente vinculados a la historia del progresivo desarrollo de la sensibilidad ética de los pueblos y, sin esa correlación, su eficacia se encuentra severamente comprometida [...]. Por esto mismo, una ley que no obtenga eficacia en este campo, es decir, que no consiga representar, interpelar y controlar la ética de las personas y las ideas corrientes sobre lo que es decente o indecente, bueno o malo, no tendrá vigencia real y será necesariamente una ley sin eficacia normativa. ${ }^{35}$

É, portanto, essa sua dimensão simbólica que se abre à associação direta entre o que a lei não só regula, mas também prescreve em termos de inovadoras práticas e experiências sociais ao colocar à mão das pessoas um repertório de nomes sancionados, validados, dotados de poder para criar novas realidades, uma vez que o código jurídico é fundante da nação. Esse seria um dos pontos fundamentais da eficácia da LMP, que se mostra democrática exatamente quando se evidenciam as condições de dar conta, em seu acesso e uso, das complexidades da vida humana e do seu sofrimento, por intermédio do conhecimento desenvolvido em outros campos disciplinares, que não só o Direito, e na militância dos movimentos sociais para alçá-los à grandeza do corpus legislativo nacional e proteger grupos minoritários.

Esta me parece una concepción mucho más democrática de la función jurídica: si la teoría no solamente describe la realidad sino que también la prescribe, estaríamos precisamente sancionando una forma de entender el derecho como asunto de todas las personas, puesto que, si bien solamente algunas pueden ser 'operadoras del derecho', todas pueden ser 'operadoras del discurso del derecho'.

Enfim, a eficácia da LMP também está ancorada na capacidade de mudar e de criar representações das quais podem se derivar novas práticas jurídicas que interferem na posição dos sujeitos que lidam diretamente com as leis, assim como de influenciar as pessoas que possam ser por elas orientadas, balizadas ou reguladas. A aplicação eficaz da lei verifica-se, então, para além da perspectiva quantitativa. Ou seja, embora desde 2006 até 2013 já tenham sido expeditas, aproximadamente, 500 mil medidas protetivas e sua efetividade na aplicação tenha atingido, aproximadamente, 50\%, esses dados repercutem na necessidade de mudanças no repertótio das atividades, seja da área de segurança, seja do Ministério Público, seja do Poder Judiciário.

No entanto, vale registrar que nem sempre esse tipo de recurso é bem visto na sua execução, uma vez que os/as agentes públicos/as envolvidos/as ainda não desenvolveram compreensão para o tratamento da violência contra a mulher na perspectiva de gênero e

${ }^{35}$ Rita Laura SEGATO, 2010, p. 130.

${ }^{36}$ SEGATO, 2010, p. 136.

514 Estudos Feministas, Florianópolis, 23(2): 501-517, maio-agosto/2015 
feminista. Em síntese, faz-se necessário a criação de outro modelo cultural-político no âmbito do Poder Judiciário, em consonância com o espírito da Convenção Belém do Pará, que abriga a LMP.

A lei, percebida no seu poder de propaganda e no seu poder persuasivo da dimensão simbólica, incide na moral, nos costumes e no substrato prejudicial de onde emanam as violências. ${ }^{37}$ Não é mais aceitável que aqueles/as que representam e que respondem pelo Estado respaldem-se na neutralidade em busca da eficácia jurídica, tendo como referente uma ideologia consensual ou mesmo arrolando-se o lugar de guardiões/ãs da tão falada, pelo senso comum, célula mater da sociedade - a família. No fundo, acabam por contribuir com a reprodução da moralidade e da lógica patriarcal, mantendo formas dissimuladas de opressão às mulheres.

Por isso, vislumbrar a consolidação da Política Nacional de Enfrentamento à Violência contra as Mulheres, por meio da plena aplicação da Lei Maria da Penha em articulação com a Convenção Belém do Pará e por meio da efetividade das ações correlatas de outras políticas públicas, significa, por um lado, o Estado brasileiro comprometer-se, pública e internacionalmente, a enfrentar e erradicar a violência contra a mulher, através de medidas, compromissos e ações efetivas, e, por outro lado, a atuar para colher estatísticas cada vez menores de ocorrência dos casos que aí se enquadram. Mas é também considerar, qualitativamente, como as letras da Lei ganham sentido no dia a dia e como são utilizadas por todos/as integrantes da sociedade, dos/as magistrados/as e procuradores/as às pessoas sem instrução formal, para o reconhecimento de suas vivências e para ajudar-lhes em sua busca por uma vida justa e melhor.

\section{Referências}

ABRAMOVAY, Miriam. "Uma conferência entre colchetes". Revista Estudos Feministas, Rio de Janeiro: IFCS/UERJ - PPCIS/UERJ, v. 3, n. 1, p. 212-218, 1995.

ARNAUD, André-Jean (Org.). Dicionário enciclopédico de teoria e de sociologia do direito. Rio de Janeiro: Renovar, 1999.

BARSTED, Leila Linhares. "O Direito Internacional e o movimento de mulheres". Revista Estudos Feministas. Rio de Janeiro: IFCS/UFRJ - PPCIS/UERJ, v. 3, n. 1, p. 191-197, 1995.

"Lei e realidade social: igualdade $x$ desigualdade". In: CEPIA (Org.). As mulheres e os Direitos Humanos. Traduzindo a legislação com a perspectiva de gênero. Rio de Janeiro: Cepia, 2001, p. 29-45.

"A resposta legislativa à violência contra as mulheres no Brasil". In: ALMEIDA, Suely (Org.). Violência de gênero. Rio de Janeiro: Editora UFRJ, 2007. p. 119-137.

BARSTED, Leila Linhares; PITANGUY, Jacqueline. O progresso das mulheres no Brasil 20032010. Rio de Janeiro: CEPIA; Brasília: ONU Mulheres, 2011.

BOUTROS-GHALI, Boutros. "Introduction". In: The United Nations and the Advancement of Women - 1945-1996. New York: United Nations Department of Public Information, 1996.

BRASIL. Câmara dos Deputados. Decreto Legis/ativo n 107, de 1995. Disponível em: http:// www2.camara.leg.br/legin/fed/decleg/1995/decretolegislativo-107-31-agosto-1995364335-publicacaooriginal-1-pl.html. Acesso em: 10 maio 2014.

Presidência da República. Lei $n^{\circ}$ 11.340, de 7 de agosto de 2006. (Lei Maria da Penha). Cria mecanismos para coibir a violência doméstica e familiar contra a mulher... Disponível em: http://www.planalto.gov.br/ccivil_03/_ato2004-2006/2006/lei//1 1340.htm. Acesso em: 20 maio 2014.

\footnotetext{
${ }^{37}$ Segato, 2003.
} 
Secretaria de Políticas para as Mulheres. 2014. Disponível em: http:// www.planalto.gov.br/ccivil_03/Projetos/EXPMOTIV/SMP/2004/16.htm. Acesso em: 18 nov. 2014.

CEDAW - 1974. Convenção sobre a eliminação de todas as formas de discriminação contra a mulher. Texto publicado no Diário do Congresso Nacional Brasileiro em 23.06.1994. Disponível em: http://www.salvador.ba.gov.br/images/PDF/convencao_cedaw.pdf . Acesso em: 10 out. 2014.

CONVENÇÃO INTERAMERICANA para prevenir, punir e erradicar a violência contra a mulher - Convenção de Belém do Pará, 1994. Disponível em: http://www.pge.sp.gov.br/ centrodeestudos/bibliotecavirtual/instrumentos/belem.htm. Acesso em: 16 out. 2014.

CORRÊA, Sonia. "Agenda para o Futuro. Lógica do passado e fundamentalismos obscurecem debate". In: CNDM, Beijing 1995. O século XXI começa na IV Conferência Mundial da Mulher. Brasília: Conselho Nacional dos Direitos da Mulher, Brasília, 1995. p. 27-34.

COSTA, Patrícia Gay Pepper da. A inserção da categoria de gênero nas relações internacionais: contribuição brasileira à Conferência de Beijing'95. 1997. 140 p. Dissertação (Mestrado em Relações Internacionais) - Universidade de Brasília, Brasília,1997.

DATASENADO. Violência Doméstica e Familiar Contra a Mulher. Senado Federal, Secretária de Transparência. Brasília, março de 2013. Disponível em: http://www.senado.gov.br/senado/ datasenado/pdf/datasenado/DataSenado-Pesquisa-Violencia_Domestica_contra_a_ Mulher_2013.pdf. Acesso em: 16 out. 2014.

FOLHA DE SÃO PAULO. Folha cotidiano. Caderno C, p. 5. São Paulo, 6 de maio de 2001.

FRASER, Nancy. "Redistribuição ou reconhecimento? Classe e status na sociedade contemporânea". Interseções - Revista de Estudos Interdisciplinares, UERJ, ano 4, n. 1, p. 7-32, 2002.

GUARNIERI, Tathiana Haddad. "Os direitos das mulheres no contexto internacional da criação da ONU (1945) à Conferencia de Beijing (1995)". Revista Eletrônica da Faculdade Metodista Granbery, n. 8, 2010. Disponível em: http://re.granbery.edu.br. Acesso em: 20 maio 2014.

GUIA PARA LAAPLICACIÓN de la Convención Interamericana para Prevenir, Sancionar y Erradicar la Violencia contra la Mujer. Convención de Belém do Pará. México, 2014. Disponível em: http://www.oas.org/es/mesecvi/docs/BdP-GuiaAplicacion-Web-ES.pdf. Acesso em: 2 dez. 2014.

MAZZUOLI, Valerio de Oliveira; BIANCHINI, Alice. Lei de violência doméstica e familiar contra a mulher (Lei Maria da Penha): constitucionalidade e convencionalidade. Disponível em: http://www.oab.org.br/editora/revista/users/revista/1242740418174218181901.pdf. Acesso em: 12 out. 2014.

OBJETIVOS DE DESENVOLVIMENTO DO MILÊNIO. Relatório Nacional de Acompanhamento. Brasília: Ipea, 2010.

PATRIOTA, Tania. Relatório da Conferência Internacional sobre População e Desenvolvimento. Plataforma de Cairo, 1994. Disponível em: http://www.unfpa.org.br/Arquivos/relatoriocairo.pdf. Acesso em: 12 jun. 2014.

POOLE, Linda. Génesis de la Convención de Belém do Pará: educar y promover el rechazo a la violencia. Suplemento Todas (Suplemento Especial octubre de 2013). Instituto Nacional de Mujeres de México (Inmujeres). Disponível em: http://www.inmujeres.gov.mx/ images/stories/todas/todasmilenio especial.pdf. Acesso em: 9 set. 2014.

ROQUE, Margarita. Historia de la Comision Interamericana de Mujeres 1928-1997. Washington, D.C: CIM/OEA, 1998.

SEGATO, Rita Laura. "La argamasa jerárquica: violencia moral, reproducción del mundo y la eficacia simbolica del derecho" In: . Las estructuras elementares de la violencia: ensayos sobre género entre la antropología, la psicanálisis y los derechos humanos. Buenos Aires: Universidad Nacional de Quilmes, 2003. p. 107-130.

516 Estudos Feministas, Florianópolis, 23(2): 501-517, maio-agosto/2015 
"El derecho a nombrar el sufrimiento en el derecho". In: ETCHEGOYEN, Aldo (Comp.). Voces y silencios de la discriminación. Acceso a la Justicia. Conferencia 2009. Buenos Aires: El Mono Armado, 2010. p. 132-150.

[Recebido em 6 de janeiro de 2015 e aceito para publicação em 5 de fevereiro de 2015]

Twenty Years of the Convention of Belém do Pará and of the Law Maria da Penha Abstract: In 2014, the Convention on the Prevention, Punishment and Eradication of Violence against Women (Convention of Belém do Pará) completed two decades. The Convention is the basis of the Brazilian Law 11.340 (Maria da Penha's Law) and remains the central reference for understanding the social and legal dimensions of its effectiveness. In celebration of these 20 years, it is possible to see a more precise comprehension of the Convention and its deployments achieved by the initiatives of signatory States. The refinement of its terms and principles will influence laws and measures adopted within national sovereignty. Therefore, this paper develops a reflection on the Convention and its current importance to combating violence against women in Brazil, indicating the way forward to the scope of Maria da Penha's Law.

Key Words: Convention of Belém do Pará; Maria da Penha's Law; Social and Legal Dimensions of Its Effectiveness. 